\title{
The assessment of heavy metal contamination of landfill soil of Meshgin city using index of geoaccumulation and contamination factor
}

\author{
Fereshteh Ali Akbari
}

Department of Applied Plant Sciences (Horticulture), Babasaheb Bhimrao Ambedkar University, Central Faculty of Persian Literature and Foreign Languages, Islamic Azad University Tabriz, Iran

\begin{abstract}
Nature is one of the most important and valuable soil resources and its pollution causes irreparable damages to the environment. Municipal waste landfills produce leachate that infects soil, surface and adjacent ground waters. Landfill operations, on the Meshgin city landfill just do not care that can be a source of serious pollution. The aim of this study was to investigate soil contamination by heavy metals like chromium, cadmium and lead in landfills of Meshgin city of Ardabil province using index of geoaccumulation and contamination factor. In this study, 10 soil samples individually in the summer and autumn were collected from the study area and concentrations of chromium, cadmium, copper-phosphorous were measured using a spectrophotometry. Index of geoaccumulation and contamination factor were used to determine the level of pollution in the study area. The results showed that the index of geoaccumulation for all metals in both summer and winter were mostly $<0$, therefore the metal concentrations in soil were linked to their natural origin. Contamination factor values showed that most samples were in no pollution to moderate contamination class.
\end{abstract}

KEY WORDS: INDEX OF GEOACCUMULATION, CONTAMINATION FACTOR, POLLUTION, HEAVY METALS, MESHGINSHAHR

\section{INTRODUCTION}

Soil as a non-renewable natural resource is degraded, which eventually leads to a decrease in agricultural productions. Soil is one of the most important and valuable natural resources. Without healthy soil life on earth would not be possible. 95\% of human food comes from the land, in addition to supplying food, soil has clari- fiers property as well. The important soil contaminants, include heavy metals, acid rains and organic precipitation (Yalcin et al,2007).

Among these heavy metals are known to be important because they are non-biodegradable and have physiological effects on living organisms at low concentrations (Adriano, 1986). Heavy metals naturally exist in varying amounts in the environment. The amount of

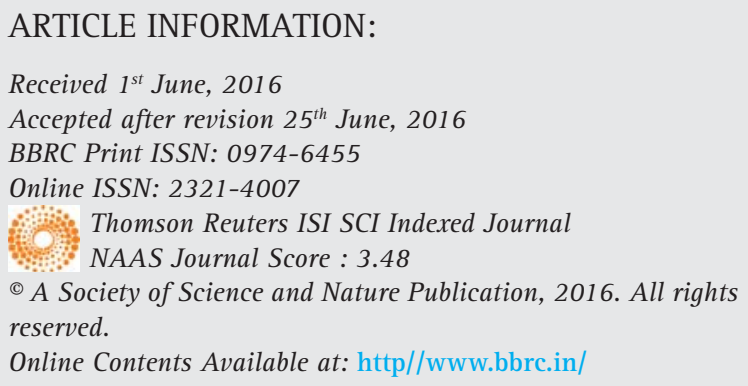


them in the soil is different affected by many factors, such as parental rock, the presence of pollution sources, application of organic and chemical fertilizers in agriculture and the use of industrial and urban waste water (Mir Ghafari, 2005).

The change of the place of heavy metal components in surface soil can be depend on parental rock soil materials and human sources, in other word these materials exist naturally in the soil but can be added by human activities, In fact, human activities may lead to the accumulation of heavy metals in soil (Yalcin et al , 2007). Due to the harmful effects of heavy metals on human health and environment, assessing heavy metal pollution is of great importance.

Assessment of heavy metal pollution is done by using different indicators, including Index of geoaccumulation, Normalized enrichment factor, Degree of contamination, Contamination factor and Pollution load index (Krzysztof et al, 2004). Yongming et al, (2006), in the assessment of urban dust pollution using normalized enrichment factor and cluster analysis declared that the origin of silver and magnesium is residential and commercial, source of chromium, copper, lead, zinc and antimony are industrial and traffic and origin of arsenic and manganese are soil production processes.

Delijani et al, (2009) investigated the enrichment and distribution of heavy metals in the soil of special economical region of South Pars (Aslaviyeh), Iran, and assessed the soil pollution in the region using factors of: Enrichment factor and Index of geoaccumulation. The results showed that the metals cadmium, lead and cobalt have highest and copper, iron and chromium have lowest enrichment among the examined soils. Bhuiyana and colleagues (2005) examined the heavy metal pollution in agricultural soil using several indicators; index of geoaccumulation and pollution load index. The results showed a significant enrichment of the soil with titanium, manganese, zinc, lead, arsenic, iron, strontium and antimony was derived from the mining activities input, (Bhuiyana, et al., 2005 ).

Given the importance of awareness of the enrichment of heavy metals in soils several studies have been conducted in the country. With regard to wheat production in the soil around the landfill area of present investigation, which eventually reaches directly or indirectly to human consumption, the necessity of this research is more and more evident.

\section{MATERIALS AND METHODS}

\section{AREA OF THE STUDY}

Meshginshahr is situated in longitude 47 degrees and 20 minutes to 48 degrees and 15 minutes, and lati- tude 38 degrees and 11 minutes to 38 degrees and 55 minutes. In terms of location, it is in the North West of Ardebil province which is limited from the north to the Moghan, from the south to the Sabalan mountain ranges, from the east to the Ardabil city and the Soviet Union and from the west to the Ahar city. This township's height is of 1830 meters above sea level. Meshginshahr covering an area of 3825 square kilometers, is the first township in the province accounted for 21.4 percent. Based on the country divisions this township has three cities (Razey, Meshginshahr, Lahrood) 3 districts (Razey, Meshginshahr, Lahrood), 12 rural areas and 404 villages (Mohammadpoor, 2012 ). In Table A municipal waste disposal site features of Meshginshahr is presented.

\begin{tabular}{|l|l|}
\hline \multicolumn{2}{|l|}{$\begin{array}{l}\text { Table 1: Municipal waste disposal site features of } \\
\text { Meshgin }\end{array}$} \\
\hline Meshginshahr & City name \\
\hline 1830 & Height from sea level \\
\hline $\begin{array}{l}\text { Meshginshahr - Aq } \\
\text { Aghbolagh - Valley } \\
\text { Dolmelar }\end{array}$ & Address of landfill \\
\hline 4 ha & Extent \\
\hline $\begin{array}{l}\text { Shallow to medium } \\
\text { depth soil }\end{array}$ & Soil type \\
\hline 32.5 & Underground water depth (m) \\
\hline 242 & The average annual rainfall \\
\hline 1807 & $\begin{array}{l}\text { Distance from the first housing } \\
\text { unit }\end{array}$ \\
\hline 19440 & $\begin{array}{l}\text { The amount of waste produced } \\
\text { annually (tons) }\end{array}$ \\
\hline
\end{tabular}

\section{SAMPLING AND ANALYSIS OF SOIL SAMPLES}

Meshginshahr landfill soil samples from 10 sites were selected in summer and autumn. In a way that two stations within the landfill itself, 6 stations around the landfill and two stations away from the landfill area (2 $\mathrm{km})$ was chosen. Soil samples were taken from depths of 0 to $25 \mathrm{~cm}$ (Rodojvic et al,1999) .in sampling of the soil a pipe of stainless steel equipped with a piston was used for extracting about $15 \mathrm{gr}$ soil (Miller,1995). The samples in the pet bottles after being washed with detergent and then being washed with pure water was transported to the laboratory (Rodojvic et al,1999). Soil samples were passed through a $2 \mathrm{~mm}$ sieve and were prepared for analysis. The samples were analyzed using HNO3 and HCL (Cao, et al, 1984 ). The concentration of heavy elements were measured using atomic absorption spectrophotometer (Model A Analyst 700). 


\section{SOIL ASSESSMENT OF THE STUDY AREA}

In this study, different criteria (CF, geoaccumulation index) was used to investigate the rate of soil pollution with heavy metals. Geoaccumulation index which has been introduced by Müller (Muller, 1969), is an indicator that can determine the degree of soil pollution and is calculated by the following equation:

$$
\text { Formula (1) Igeo }=\log _{2}((\mathrm{Cn}) / \times 1 / 5 \mathrm{Bn})
$$

Based on geoaccumulation index (Igeo) of Muller, Cn, is the concentration in sediment and soil, and Bn, is the field concentration level (Muller, 1969). Using formula (1) geoaccumulation index for soil samples of the study was calculated. In this respect for the correction of the effects of parental materials of the soil and natural fluctuations of given matter content in nature and small changes caused by human activities, the correction factor of 1.5 was used. Muller 6 classes was considered for geoaccumulation index (Table 2).

\begin{tabular}{|l|l|}
\hline \multicolumn{2}{|l|}{ Table 2: Classes of Index of geoaccumulation } \\
\hline $\begin{array}{l}\text { Geoaccumulation } \\
\text { index }\end{array}$ & The degree of contamination \\
\hline$<0$ & Uninfected \\
\hline $1-0$ & $\begin{array}{l}\text { Uninfected to slightly } \\
\text { contaminated }\end{array}$ \\
\hline $1-2$ & Slightly contaminated \\
\hline $2-3$ & $\begin{array}{l}\text { slightly contaminated to Too } \\
\text { polluted }\end{array}$ \\
\hline $3-4$ & Too polluted \\
\hline $4-5$ & Too polluted to highly polluted \\
\hline$>5$ & Heavily polluted \\
\hline
\end{tabular}

To determine the risk assessment of soil contamination by Contamination factor the equation (2) were used (Abrahim et al .,2008 ). Based on these factors, levels of contamination can be divided between 1 and 6 based on the severity of contamination (Table 3 ).

Formula (2) $\mathrm{CF}=[\mathrm{C}]$ heavy metal/ [C]background

\section{RESULTS AND DISCUSSION}

The Index of Geoaccumulation showed that the amount of heavy metal chromium in the summer for the stations 7 and 8 were between 3 and 4 which is too contaminated and for the rest of the stations were $<0$, which represents the un-infected. The amount of heavy metal lead in the stations $2,3,6,9,10$ were $<0$ which shoes uninfected and for the rest of the stations were between 0-1which rep-
Table 3: Classification of contamination factor values

\begin{tabular}{|l|l|}
\hline $\begin{array}{l}\text { Degree of } \\
\text { geoaccumulation }\end{array}$ & The degree of contamination \\
\hline 0 & No pollution \\
\hline 1 & No pollution to moderate contamination \\
\hline 2 & The moderate contamination \\
\hline 3 & Moderate to strong pollution \\
\hline 4 & Strong pollution \\
\hline 5 & Strong to very strong pollution \\
\hline 6 & Very strong pollution \\
\hline
\end{tabular}

resent non infected to slightly contaminated. Beside the amount of heavy metal of cadmium pollution at station 1 was uninfected and at station 10 was slightly contaminated, and at stations 8 and 7 were too polluted to highly polluted and at other stations were slightly to very polluted (Figure 1).

Geoaccumulation index showed that the degree of contamination of heavy metal chromium in the fall for stations 7 and 8 were very polluted and for station 4 was non-polluted to slightly contaminated and for the remaining stations were unpolluted. The amount of heavy lead at station 10 was at uninfected level and at stations 2, 6, 8, 7 were at slightly contaminated and uninfected to slightly contaminated for the rest stations. The amount of heavy cadmium at stations 7 and 8 were at the very polluted level and at stations 5, 1, and 6 were at the level of un infected to the slightly contaminated it was and un-contaminated for the rest of the stations (Figure 2).

Results of contamination factor during the summer showed that most of the stations were in no pollution to moderate contamination class. The contamination factor in the study area for chromium metal shows that 20\% of the data were in the class no pollution class, 20\% in very strong pollution class and $60 \%$ in class no pollution to moderate contamination class. For cadmium, $20 \%$ of data were classified in moderate to strong class, $20 \%$ in very strong class, 50\% in no pollution class and $10 \%$ were classified in strong pollution to very strong. For lead $20 \%$ of data classified in no pollution category, and $80 \%$ in no pollution to moderate contamination class. The results showed a significant enrichment of the soil with titanium, manganese, zinc, lead, arsenic, iron, strontium and antimony was derived from the mining activities input, (Bhuiyana, et al., 2005 ).

Beside the results of contamination factor in the fall showed that most of the stations were in categories of no pollution to the moderate contamination. Factor value for chromium in the study area showed that $80 \%$ of data were in class of no pollution to moderate contamination and $20 \%$ in the class of very strong pollution. For 

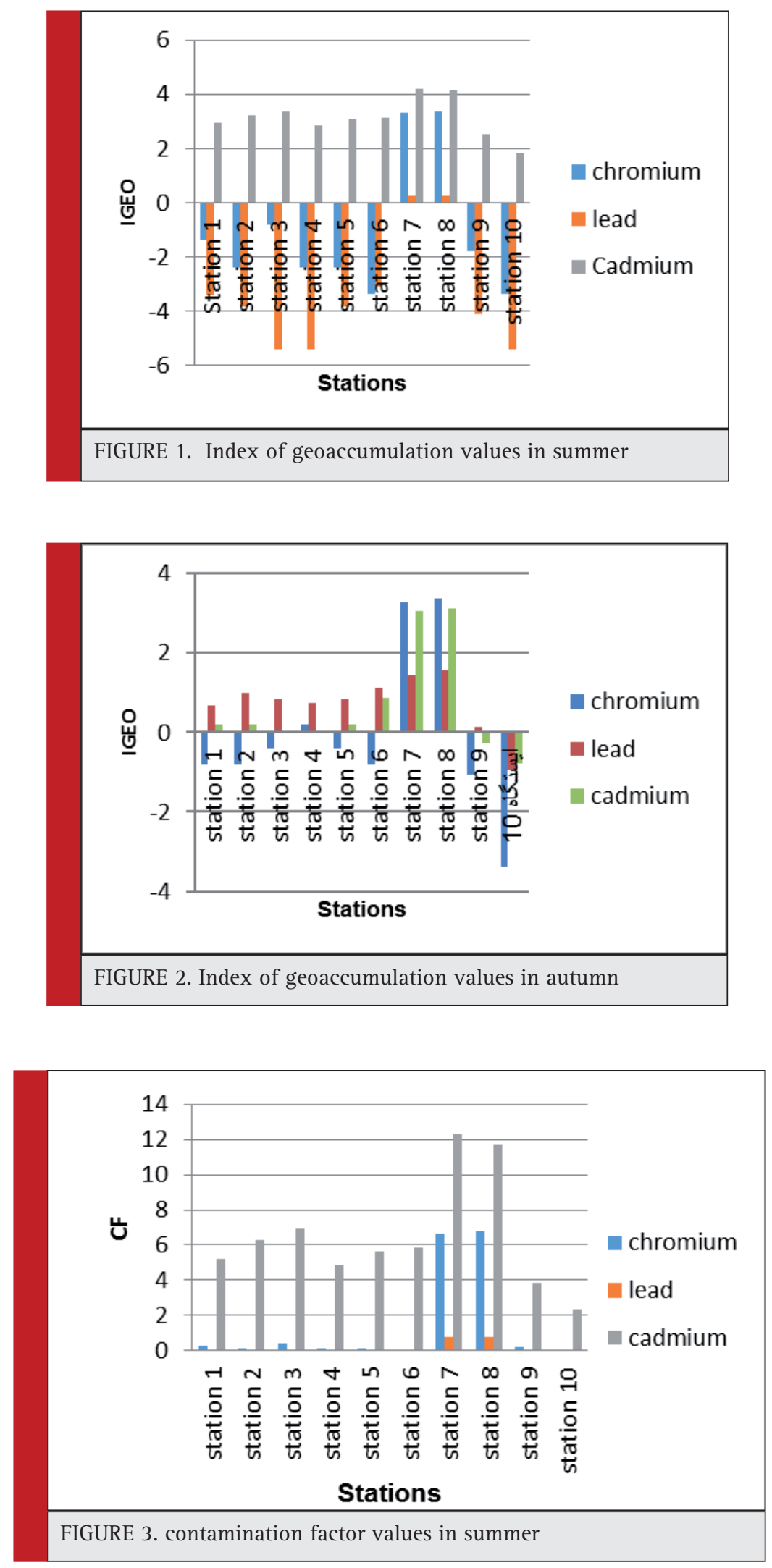


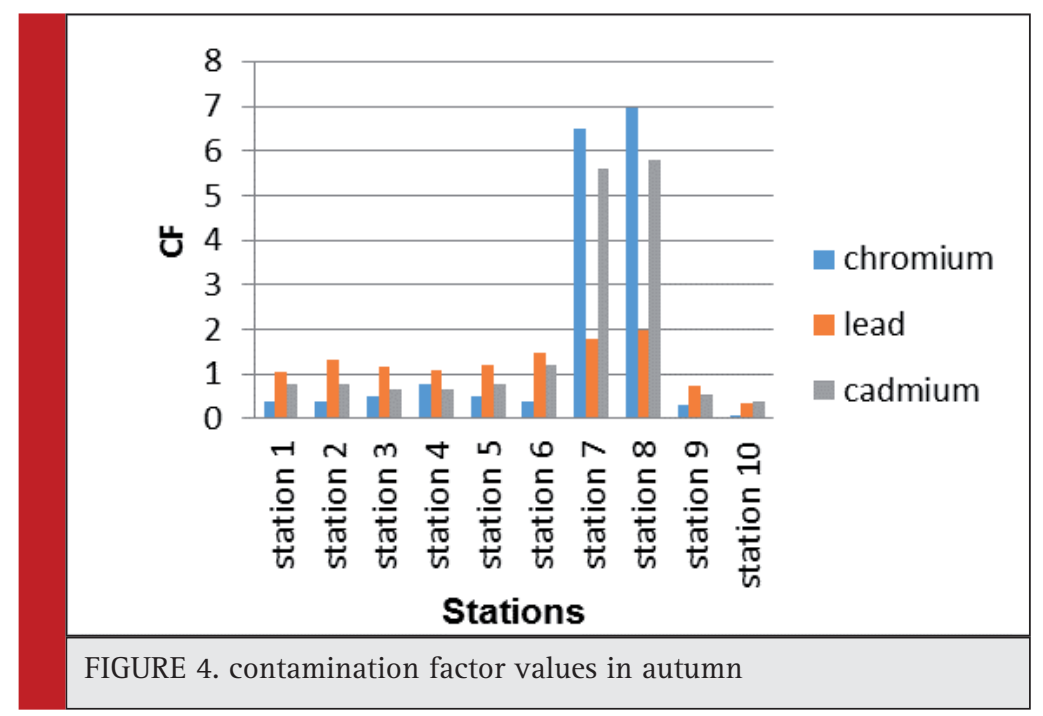

the cadmium 70\% of the data were in no pollution to moderate contamination class and 20\% in strong pollution class and $10 \%$ in moderate contamination class. For Lead $\mathrm{Pb} 90 \%$ of the data were in no pollution to moderate contamination class and 10\% were in moderate contamination class.

\section{CONCLUSION}

The assessment of the degree of pollution Showed that the amount of the Index of accumulation for chromium metal in the summer at stations 8 and 7 were too contaminated and at rest of the stations were uninfected, but for all metals in both seasons mostly $<0$ were obtained, which represents the uninfected level. As a result, the concentration of heavy metals in soil were linked to their natural origin. But the pollution at stations 7 and 8 can be associated with the accumulation of heavy metals in landfill leachate. Contamination factor values showed that most of the samples were in Boone pollution class to moderate pollution. Contamination factor value for cadmium was the highest.

\section{REFERENCES}

Abrahim, G.M.S. and Parker R.J. (2008). Assessment of heavy metal enrichment factors and the degree of contamination in marine sediments from Tama Estuary, Auckland, New Zealand. Environ Monit Assess, 136: 227-238.

Adriano, D.C. (1986) Trace Elements in the Terrestrial Environment Springer-Verlag New York.

Bhuiyana, M.A.H, Parvez, L. Islam, M.A. Dampare, S.B. and Suzukia, S . Zolo (2005) Heavy metal pollution of coal mine- affected agricultural soils in the northern part of Bangladesh Journal of Hazardous Materials, 173: 384-392

Cao, H.F. Change, A. C. and Page, A. L. (1984). Heavy Metal Contents of Sludge-treated Soils as Determined by Three Extraction Procedures, J Environ Qual, 13(4):632-634.

Delijani F., Kazemi,GH, Parvinnia, M., Khakshour, M.( 2009). Enrichment and distribution of heavy metals in the soils of South Pars Special Economic Energy Zone (Assaluyeh), the eighth International Congress on Engineering 21-23, May, Shiraz University, Shiraz, Iran, 1-8.

Krzysztof L., Danuta L. and Irena K. (2004). Metal contamination of farming soils affected by industry. Environment International, 30:159-165.

Miller, R.W. \& Donahue, R.L. (19950 Soil in our Environment,7th Edition, Prentice Hall, London, pp.346-362.

Mir Ghafari, N. 2005, Lead Concentration in the number of plant species in the natural surroundings of Sorkh lead and zinc mine, Journal of Natural Resources (3) (58), 635-642.

Mohammadpoor, R. (2012). Evaluation of urban landfills Ardebil Province using Alanku, Master Thesis, Islamic Azad University, Science and Research.

Muller, G .(1969).Index of geo accumulation in sediment of the Rhine River .Geojournal, 2 : 108-118.

Rodojvic M., V.N., Bashkin, (1999) Practical Environmental Analysis, the Royal Society of Chemistry, 466p.

Yalcin, M.G.; Battaloglu, R. and I lhan, S. (2007) Heavy metal sources in Sultan Marsh and its neighborhood, Kayseri, Turkey. Environ Geol, 53:399-415.

Yongming H., Peixuan D., Junji C. and Posmentier E.S. (2006) Multivariate analysis of heavy metal contamination in urban dusts of Xi'an, Central China. Science of The Total Environment, 355:176-186. 